\title{
In Ovo Delivered Toll-Like Receptor 7 Ligand, Resiquimod Enhances Host Responses against Infectious Bronchitis Corona Virus (IBV) Infection
}

\author{
Upasama De Silva Senapathi ${ }^{1}$, Mohamed Aboelkhair ${ }^{2}$, Kekungu Puro ${ }^{3}$, Mariam Ali ${ }^{1}$, \\ Aruna Amarasinghe ${ }^{1}$, M. Sarjoon Abdul-Cader ${ }^{1}$, Guido Van Marle ${ }^{4}$ (D), Markus Czub ${ }^{1}$ \\ and Mohamed Faizal Abdul-Careem 1,* \\ 1 Department of Ecosystem and Public Health, Faculty of Veterinary Medicine, University of Calgary, \\ Health Research Innovation Center 2C53, 3330 Hospital Drive NW, Calgary, AB T2N 4N1, Canada; \\ yaseshwari.desilvase@ucalgary.ca (U.D.S.S.); mariam.ali3467@gmail.com (M.A.); \\ arunavetlk@gmail.com (A.A.); \\ mohamedsarjoon.moham@ucalgary.ca (M.S.A.-C.); mmczub@ucalgary.ca (M.C.) \\ 2 Virology Department, Faculty of Veterinary Medicine, University of Sadat City, 999060 Sadat, Egypt; \\ maboelkhair2004@yahoo.com \\ 3 Division of Animal Health, ICAR Research Complex for NEH Region, Umiam, 793103 Meghalay, India; \\ akulepuro@rediffmail.com \\ 4 Department of Microbiology, Immunology and Infectious Diseases, Cumming School of Medicine, \\ University of Calgary, 3330 Hospital Drive NW, Calgary, AB T2N 4N1, Canada; vanmarle@ucalgary.ca \\ * Correspondence: faizal.abdulcareem@ucalgary.ca; Tel.: +403-220-4462
}

Received: 21 March 2020; Accepted: 13 April 2020; Published: 15 April 2020

\begin{abstract}
Toll-like receptor (TLR) 7 ligand, resiquimod, has been studied as an adjuvant and antiviral agent against several pathogens in chicken. Yet, the effectiveness of resiquimod against infectious bronchitis virus (IBV) infection has not been evaluated. In this study, we investigated the effectiveness of resiquimod delivered pre-hatch (in ovo) against IBV infection post-hatch identifying key mechanisms involved in resiquimod driven immune activation. First, we found an upregulation of interleukin (IL)- $1 \beta$ and interferon (IFN)- $\gamma$ mRNA levels and considerable expansions of macrophage and cluster of differentiation (CD) $8 \alpha+$ T cell populations in lungs of chicken as early as day one post-hatch, following pre-hatch delivery of resiquimod. Second, we observed that resiquimod was able to act as an adjuvant when resiquimod was delivered pre-hatch along with an inactivated IBV vaccine. Finally, when the resiquimod pretreated one-day-old chickens were infected with IBV, reduction in viral shedding via oral and fecal routes was observed at 3 days post- infection. Overall, this study shows that the pre-hatch delivered resiquimod increases cell-mediated immune responses in lungs with an advantage of reduction in IBV shedding.
\end{abstract}

Keywords: in ovo; resiquimod; avian macrophage; $\mathrm{CD} 8 \alpha+$ cell; infectious bronchitis virus; interleukin $1 \beta$; interferon $\gamma$

\section{Background}

Infectious bronchitis (IB) is one of the major respiratory diseases that impacts chickens (Gallus gallus domesticus) worldwide [1-3]. In spite of immunization, IB remains a considerable cause of economical loss to the poultry industry [4]. Therefore, alternative strategies that aim to boost the host responses against IBV are increasingly being investigated.

Toll-like receptor (TLR) ligands, a group of innate immune response modifiers have become worthy candidates that have been exploited to enhance innate immune responses in hosts against a number 
of pathogens [5]. TLRs are a subset of germline-encoded pattern recognition receptors found in mammals, birds, and fish. Upon infection, TLRs are able to recognize and bind to pathogen-associated molecular patterns (PAMPs), which are highly conserved molecular structures present in microbes. These PAMP-TLR receptor interactions trigger a cascade of intracellular interactions that results in the upregulation of a range of genes responsible for innate immune activation. Thirteen different types of TLRs have been identified in mammalian cells. Of those, TLR3, TLR4, TLR5, and TLR7, which are found in birds, are comparable to mammalian counterparts and TLR1La, TLR1Lb, TLR2a, TLR2b, TLR15 appear to be present only in birds [5,6], whereas TLR21 is present in both birds and fish [7].

Among the TLRs, TLR3, 7 and 21 in mammals and birds are known to be localized within the endosomal compartment [5]. TLR7 exclusively recognizes and binds with either ssRNA components that are rich in GU (guanosine-uridine) or poly-U rich sequences or their synthetic analogs, resiquimod, and imiquimod [8]. Resiquimod, one of the above mentioned imidazoquinoline compounds is a potent synthetic TLR7 and TLR8 agonists that stimulate the production of type I and II interferons (IFNs), interleukin (IL)-4, IL-12, IL-1 $\beta$, inducible nitric oxide synthase (iNOS), and tumor necrosis factor alpha $(\mathrm{TNF}-\alpha)[9-12]$.

The ability of these synthetic analogs to be delivered in ovo (embryo day 18 (ED18)), as a standalone agent or as a vaccine adjuvant, to provide prophylaxis has several advantages over conventional delivery methods $[13,14]$. These advantages along with the superior ability of resiquimod rather than imiquimod to induce innate immune cytokines [8] have prompted investigators to direct studies in probing the potential of resiquimod against avian viruses such as infectious bursal disease virus (IBDV) [10], infectious laryngotracheitis virus (ILTV) [15], and avian influenza virus (AIV) [16,17]. Parenterally administered resiquimod is also known to act as an adjuvant against IB and Newcastle disease (ND) viral vaccines [12,18]. However, use of resiquimod as a prophylactic standalone agent for a post-hatch IBV challenge in chickens or adjuvant effect with inactivated vaccine when delivered in ovo has not been investigated previously. Therefore, we aimed at delivering resiquimod pre-hatch (in ovo) at ED18 to investigate the immune enhancement, particularly cell-recruitment and cell-mediated immune response in lungs and to ascertain the level of reduction in IBV genome load provided subsequent to post-hatch IBV infection.

\section{Materials and Methods}

\subsection{Animals}

The use of specific pathogen free (SPF) eggs, embryos, and live chickens in all our experiments have been approved by the Health Science Animal Care Committee (HSACC) (AC13-0291). The SPF eggs were purchased from the Canadian Food Inspection Agency (CFIA), Ottawa and incubated in digital egg incubators (Kingsuromax 20 and Rcom MARU Deluxe max, Autoelex Co., Ltd., GimHae, GyeongNam, Korea) according to the manufacturer's instructions. The chickens used in experiments were housed in high containment poultry isolators at the prion/virology animal facility, Health Research Innovation Center (HRIC), University of Calgary with ad libitum access to food, water, and necessary veterinary care.

\subsection{Virus and TLR Ligand}

IBV Massachusetts (M) 41 strain purchased from American Type Culture Collection (ATCC, Manassas, Virginia, United States) was used in this study. End point dilution assay was employed to assess the viral titers using embryo day (ED) 9 SPF eggs and expressed as $50 \%$ embryo infectious dose $\left(E_{1 D_{50}}\right.$ ) [19]. The synthetic analog of ssRNA, resiquimod, TLR7 ligand was purchased from Selleckchem (Houston, TX, USA). 


\subsection{Experimental Design}

2.3.1. Evaluation of Cellular and Cytokine Responses in Lungs Following In Ovo Resiquimod Treatment

To determine the mechanisms of action of in ovo delivered resiquimod in young chickens, ED18 SPF eggs were inoculated with either resiquimod ( $400 \mu \mathrm{g}$ in $200 \mu \mathrm{L}$ phosphate buffered saline or PBS (200 $\mu \mathrm{L}$ PBS alone) and incubated until hatch. On the day of hatch, coinciding with the time of potential pathogen encounter, chickens from both groups (resiquimod pretreated $=6$, PBS pretreated $=6$ ) were euthanized and lung tissue preserved in Optimum Cutting Medium (OCT, Leica Biosystems, Wetzlar, Germany) for immunofluorescent assay, in 10\% neutral buffered formalin for histopathological examination, and in RNASave ${ }^{\circledR}$ (Biological Industries, Beit Haemek, Israel) for cytokine mRNA analysis.

\subsubsection{Evaluation of Adjuvant Effect of Resiquimod}

To determine the adjuvant effect of resiquimod in young chickens, ED18 SPF eggs were inoculated with either resiquimod (ssRNA) plus inactivated IBV vaccine $(100 \mu \mathrm{g}$ of resiquimod $+5 \mu \mathrm{g}$ of inactivated IBV vaccine in $200 \mu \mathrm{L}$ PBS), inactivated IBV vaccine (5 $\mu \mathrm{g}$ in $200 \mu \mathrm{L}$ PBS), allantoic fluid (AF) $(200 \mu \mathrm{L} / \mathrm{egg})$ as vaccine control, and PBS $(200 \mu \mathrm{L} / \mathrm{egg})$ as experimental control and incubated until hatch. In ovo delivery was carried out as described previously [20]. On the day of hatch, the chickens ( $n=3 /$ group) were transferred to high containment animal isolators, reared with ad libitum feed and water. On day 12 post-hatch (12 dph), the chickens were humanely euthanized, and the lungs and spleens were collected. Subsequently, the mononuclear cells were isolated as described previously [21,22] for in vitro culture. The cells were seeded in 96-well plates with each sample ( $n=3 /$ group) in triplicate. Cells derived from lung tissue and the spleen were plated separately for the in vitro experiment. A subset of cells for both the lung and spleen cell plates were stimulated with $5 \mu \mathrm{g}$ of inactivated IBV vaccine and another subset with PBS as the control. The cells were stimulated for $48 \mathrm{~h}$ at $40{ }^{\circ} \mathrm{C}$ with $5 \%$ $\mathrm{CO}_{2}$. The supernatant was collected, and interferon (IFN)- $\gamma$ concentration was estimated by enzyme linked immunosorbent assay (ELISA) using chicken IFN- $\gamma$ cytoset kit \#CAC 1233 (Life Technologies Corporation, Frederick, MD, USA) following the manufacturer's instruction.

\subsubsection{Evaluation of IBV Genome Loads Following IBV Infection of Resiquimod Pretreated Chickens}

In ovo TLR ligand delivery was carried out as described previously [20]. Four hundred $\mu \mathrm{g}$ of resiquimod diluted in $200 \mu \mathrm{L}$ of PBS was inoculated per SPF egg on ED18 via allantoic sac route $(n=13)$, whereas the control received $200 \mu \mathrm{L}$ of PBS alone $(n=15)$. On day 1 post-hatch, the chickens $(n=10)$ from the resiquimod pretreated group and PBS pretreated group $(n=12)$ were infected with IBV M41 strain intratrachealy at a dose rate of $2.75 \times 10^{4}$ EID $_{50}$ per bird $[23,24]$ and the remaining birds were maintained as uninfected controls (Resiquimod control $=3$, PBS control $=3$ ). At 3 and 7 dpi, oropharyngeal and cloacal swabs were collected from infected birds using Puritan ${ }^{\circledR}$ Unitranz-RT transport system (Puritan Medical Products LLC Guilford, Maine, USA) and stored in $-80{ }^{\circ} \mathrm{C}$ until analyzed.

\subsection{Techniques}

\subsubsection{RNA Extraction and Complementary DNA (cDNA) Synthesis}

RNA extraction of oropharyngeal and cloacal swabs was performed using E.Z.N.A. ${ }^{\circledR}$ viral RNA kit (Omega Bio-tek Inc., Norcross, GA, USA) as per the manufacturer's guidelines. Total RNA from the lungs was extracted using Trizol reagent (Invitrogen, Canada Inc., Burlington, ON, Canada) following the manufacturer's protocol. Extracted RNA concentration was measured using a Nanodrop1000 spectrophotometer (ThermoScientific, Wilmington, DE, USA) at 260 and $280 \mathrm{~nm}$ wavelength absorbance. High Capacity cDNA Reverse Transcription Kit (Invitrogen Life Technologies, Carlsbad, CA, USA) was used as per the manufacturer's guidelines to reverse transcribe $2 \mu \mathrm{g}$ of total RNA from tissue samples and 200 ng of total RNA from swab samples. 


\subsubsection{Real-Time Reverse Transcriptase Polymerase Chain Reaction (RT-PCR) Assay}

The cytokine mRNA expression and IBV genome load quantification was carried out as described previously [24]. In brief, IBV nuclear (N) gene and cytokine genes were quantified using Fast SYBR ${ }^{\circledR}$ Green Master Mix (Invitrogen, Burlington, ON, Canada) in a RT-PCR assay. The target genes were amplified using gene specific primers (Supplementary Table S1). The Thermal Cycler (CFX96-C1000, Bio-Rad Laboratories, Mississauga, ON, Canada) conditions were $95{ }^{\circ} \mathrm{C}$ for $20 \mathrm{~s}$ (s) of pre-incubation, $95^{\circ} \mathrm{C}$ for $3 \mathrm{~s}$, and $60^{\circ} \mathrm{C}$ for $30 \mathrm{~s}$ for 40 amplification cycles. A melting curve analysis was performed between $95^{\circ} \mathrm{C}$ and $65^{\circ} \mathrm{C}$, with a $0.5^{\circ} \mathrm{C}$ raise in temperature every $5 \mathrm{~s}$. Fluorescent signal acquisition was performed at $60^{\circ} \mathrm{C}$ for $30 \mathrm{~s}$.

\subsubsection{Immunofluorescent Assay}

Immunofluorescent Assay (IFA) to detect macrophages (KUL01+), CD4+ T cells, and CD8 $\alpha+\mathrm{T}$ cells was performed as described previously [24]. In brief, the OCT preserved lung tissue sections were fixed in cold acetone for $5 \mathrm{~min}(\mathrm{~min})$ and blocked in 5\% goat serum diluted in a Trisma buffered saline (TBS) buffer at room temperature for $30 \mathrm{~min}$. The primary antibodies, the mouse monoclonal antibody specific for chicken macrophages/monocytes, KUL01+ (Southern Biotech, Birmingham, AL, USA), CD8 $\alpha$ (CT-8, Southern Biotech, Birmingham, AL, USA), were used in a 1:200 dilution in a 5\% goat serum for $30 \mathrm{~min}$. Then, the secondary antibody, goat anti-mouse $\operatorname{IgG}(\mathrm{H}+\mathrm{L})$ conjugated with Dylight $^{\circledR} 550$ (Red fluorescence, Bethyl Laboratories Inc., Montgomery, TX, USA) was used for $1 \mathrm{~h}$. For CD4+ staining, chicken CD4 antibody (CT-4, Southern Biotech, Birmingham, AL, USA) was used as the primary antibody followed by biotinylated goat anti-mouse $\operatorname{IgG}(\mathrm{H}+\mathrm{L})$ (Southern Biotech, Birmingham, AL, USA) used in a 1:250 dilution. Dylight ${ }^{\circledR} 488$ (green fluorescence) streptavidin was used as a final step followed by mounting the slides with Vectashield ${ }^{\circledR}$ mounting medium with DAPI (Vector Laboratories Inc., Burlingham, CA, USA).

\subsubsection{Inactivation of IBV and Determination of Protein Concentration}

The stock IBV virus propagated in ED9 SPF eggs was concentrated by ultra-centrifugation at $55,000 \times g$ for $3 \mathrm{~h}$ at $4{ }^{\circ} \mathrm{C}$. Then, one-tenth of the volume (after resuspending the pellet) was inactivated using formalin with a final concentration of $0.1 \%$ [25]. The protein concentration of the vaccine was determined using Bio-Rad Dc Protein Assay kit (cat\# A 500-0113, B 500-0114, C 500-0115, Bio-Rad Laboratories, Life sciences group, Hercules, CA, USA) with bovine serum albumin (BSA) as a standard.

\subsubsection{Mononuclear Cell Isolation from Lung and Spleen}

The collected spleen and lungs were rinsed multiple times in cold Hank's balanced salt solution (HBSS) to get rid of blood contamination. The spleens were homogenized, filtered through a $40 \mathrm{~mm}$ cell strainer (VWR, Edmonton, AB, Canada) and the cells were collected. The lungs were minced using sterile scalpel and forceps, to approximately $5 \mathrm{~mm}$ fragments and soaked in $400 \mathrm{U} / \mathrm{mL}$ collagenase type I solution (Sigma-Aldrich, Oakville, ON, Canada) for $30 \mathrm{~min}$ at $37^{\circ} \mathrm{C}$. Dispersed cells and tissue fragments were separated using a $40 \mathrm{~mm}$ cell strainer. The cells were pelleted at $400 \times \mathrm{g}$ for $10 \mathrm{~min}$ $\left(4^{\circ} \mathrm{C}\right)$, followed by resuspension in HBSS and carefully layered onto Ficoll Paque PLUS (GE Health Care, Mississauga, ON, Canada) making sure not to disturb the Ficoll layer in a $15 \mathrm{~mL}$ conical tube at room temperature in 1:1 ratio. The layered cells were spun for $40 \mathrm{~min}$ at $400 \times g$ at $20^{\circ} \mathrm{C}$. The mononuclear cells were collected from the interface and pelleted, washed with HBSS, and the cells were suspended in complete Roswell Park Memorial Institute (RPMI) medium-1640 (RPMI-1640 supplemented with 10\% heat inactivated fetal bovine serum, $100 \mathrm{U} / \mathrm{mL}$ penicillin and $100 \mu \mathrm{g} / \mathrm{mL}$ streptomycin), and the cells were counted. The lung and spleen mononuclear cells $\left(1 \times 10^{6}\right.$ cells/well $)$ in $120 \mu \mathrm{L}$ of complete RPMI-1640 medium were seeded into 96-well plates (Greiner Bio-one GmbH-Frickenhausan, Germany). 


\subsection{Data Analyses}

For the quantification of macrophages (KUL01+), CD4+ T cells, and CD8 $\alpha+\mathrm{T}$ cells in lung tissue, 5 areas with the most positive fluorescent signals for KUL01+, CD4+ T cells, and CD8 $\alpha+\mathrm{T}$ cells per tissue section were captured at $20 \times$ magnification along with corresponding nuclear stained (4', 6 -diamidine-2' -phenylindole dihydrochloride, DAPI) fluorescent areas. The images were quantified using Image J software (National Institute of Health, Bethesda, MD, USA). Fluorescent intensities for Dylight $^{\circledR} 550$ (KUL01+ and CD8 $\alpha+$ cells) and DyLight ${ }^{\circledR} 488$ (CD4+ cells) positive signals were expressed relative to total area (as estimated by nuclear fluorescent signal with DAPI) and given as a percentage.

\subsection{Statistical Analyses}

Group differences in viral loads in oropharyngeal and cloacal swabs were identified using linear mixed-effects model followed by a pairwise comparison using Tukey's test in R statistical software (R studio version 1.0.153, Boston, MA, USA). For identifying differences in IFN- $\gamma$ concentrations, the one-way analysis of variance (ANOVA) followed by Tukey's multiple comparisons was used. A one-tailed t-test was used to identify differences among two groups. Data in graphs are shown in the original scale of measurements. However, due to non-normality and inability to satisfy model assumptions of some datasets, log transformation was applied to these prior to analysis. GraphPad Prism Software 5 (La Jolla, CA, USA) and R statistical software ( $\mathrm{R}$ studio version 1.0.153, Boston, MA, USA) was used to perform model statistics.

\section{Results}

\subsection{Immune Cell Recruitment Following in Ovo Delivery of Resiquimod}

Immunofluorescent assay performed on lung tissue obtained at day one post-hatch, revealed a significant increase in macrophage $(p=0.007$, Figure $1 \mathrm{a})$ and $\operatorname{CD} 8 \alpha+\mathrm{T}(p=0.02$, Figure $1 \mathrm{~b})$ numbers in resiquimod pretreated chickens as compared with the PBS pretreated controls. However, CD4+ T cell numbers were not significantly different between resiquimod and PBS pretreated lungs $(p>0.05$, Figure 1c).

\subsection{IFN- $\gamma$, IL-1 $\beta$, and iNOS mRNS Expression Levels Following In Ovo Delivery of Resiquimod}

The mRNA expression levels of several cytokines in lung tissues of one-day-old chickens after pretreating ED18 SPF eggs with either resiquimod or PBS were compared. We found a significant upregulation of IFN- $\gamma$ and IL- $1 \beta$ expression levels in the day-old lung tissue of resiquimod pretreated chickens as compared with controls $(p=0.036, p=0.039$, Figure $2 a, b)$ and an increased trend in iNOS mRNA levels, although not statistically significant $(p>0.05$, Figure $2 c)$.

\subsection{IBV Shedding via Oropharyngeal and Cloacal Routes Following Infection with IBV M41 in In Ovo Resiquimod Pretreated Chickens}

The average IBV viral RNA loads of oropharyngeal and cloacal swabs were lower in resiquimod pretreated chickens at $3 \mathrm{dpi}$ and in cloacal swabs at $7 \mathrm{dpi}$ as compared with that of PBS pretreated chickens $(p<0.001$, Figure $3 a, b)$. However, we did not observe a significant difference in oropharyngeal IBV genome loads between the two groups at $7 \mathrm{dpi}(p>0.05$, Figure $3 a, b)$. 
a.
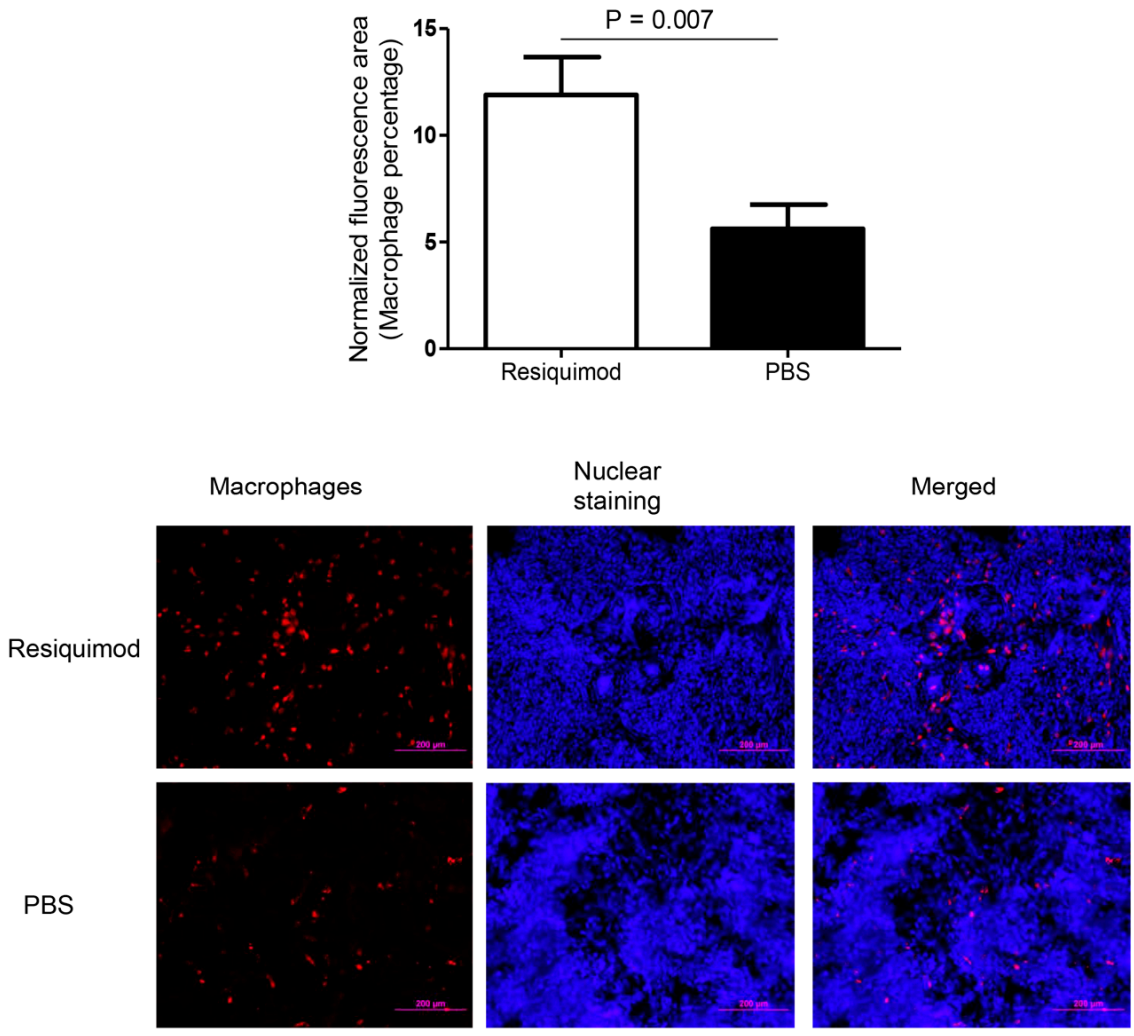

b.

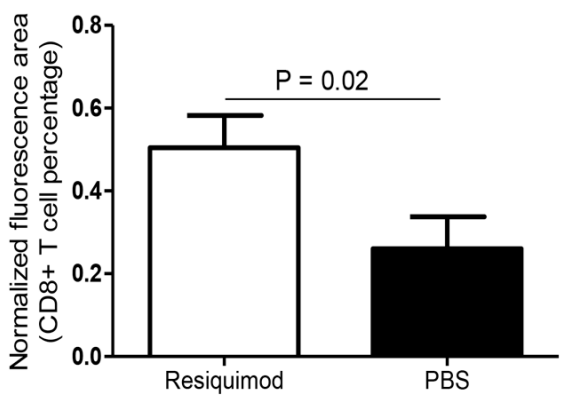

CD8+ T cells
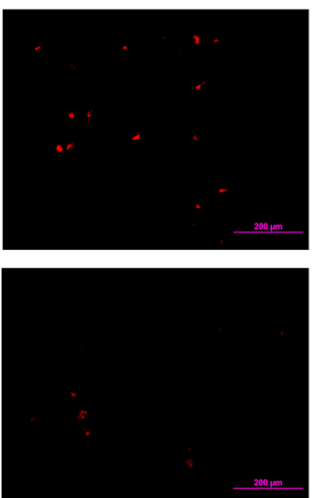

Nuclear staining
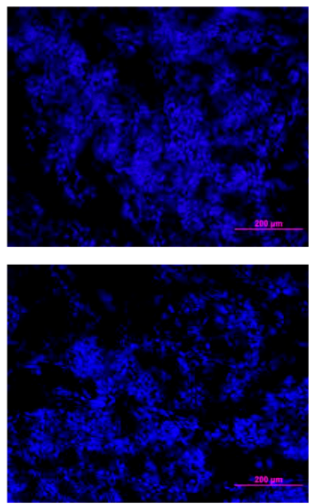

Figure 1. Cont.
Merged
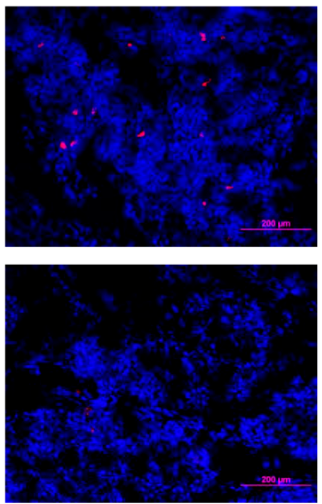

PBS 
C.
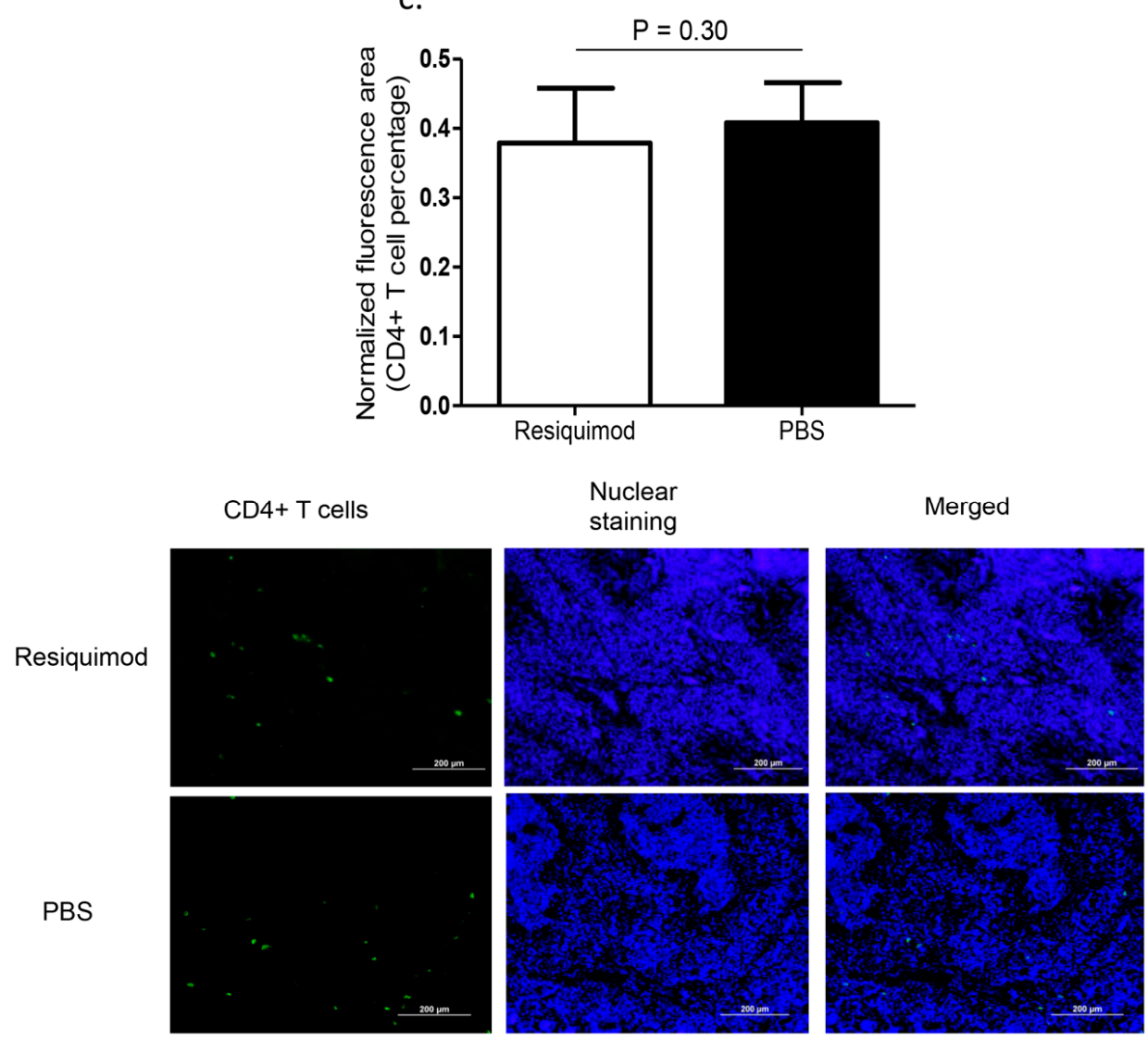

Figure 1. Immune cell recruitment following in ovo delivery of resiquimod or PBS. Embryo day 18 (ED18) specific pathogen free (SPF) eggs were treated with resiquimod $(n=6,400 \mu \mathrm{g}$ of resiquimod in $200 \mu \mathrm{L}$ of PBS per egg) or PBS ( $n=6,200 \mu \mathrm{L}$ of PBS per egg) and incubated to hatch. On the day of hatch, the birds were euthanized and lung tissue collected in Optimum Cutting Medium (OCT) compound for immunofluorescent assays. Quantitative data and representative images following immunofluorescent assay for lung (a) macrophages (red), (b) CD8 $\alpha+\mathrm{T}$ cells (red), and (c) CD4+ T cells (green) are depicted. One-tailed Student's t-test was performed to identify group differences. The differences were considered significant at $p \leq 0.05$. The error bars represent \pm standard error of mean (SEM).

a.

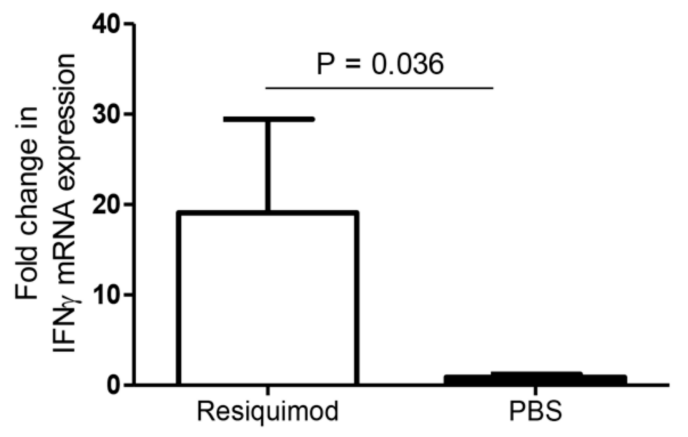

b.

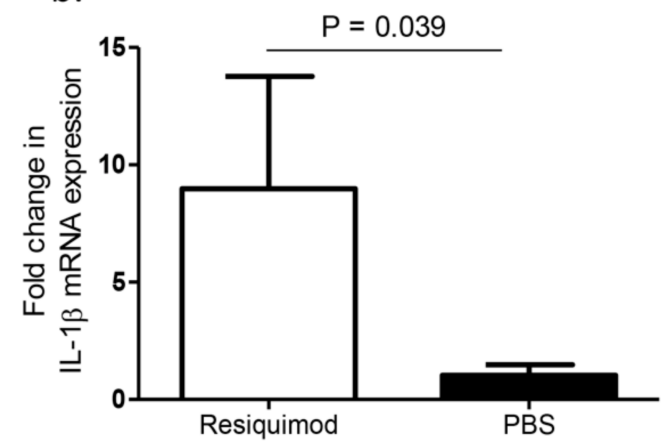

Figure 2. Cont. 


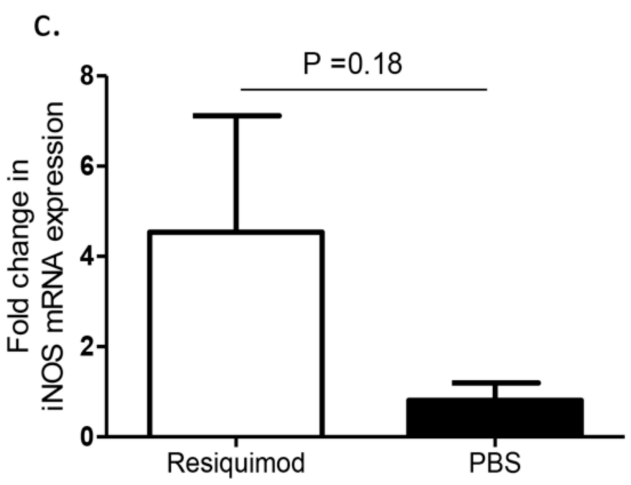

Figure 2. IFN- $\gamma$, IL-1 $\beta$, and iNOS mRNA expression levels following in ovo delivery of resiquimod or PBS. ED18 SPF eggs were treated with resiquimod ( $n=6,400 \mu \mathrm{g}$ of resiquimod in $200 \mu \mathrm{L}$ of PBS per egg) or PBS ( $n=6,200 \mu \mathrm{L}$ of PBS per egg) and incubated to hatch. On the day of hatch, birds were euthanized, and lung tissues collected to assess mRNA expressions of (a) IFN- $\gamma$, (b) IL- $1 \beta$, and (c) iNOS. One-tailed Student's t-test was performed to identify group differences. The differences were considered significant at $p \leq 0.05$. The error bars represent \pm SEM.

a.

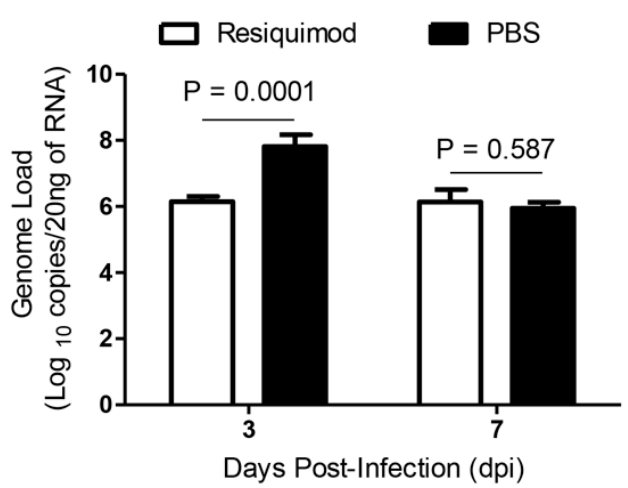

b.

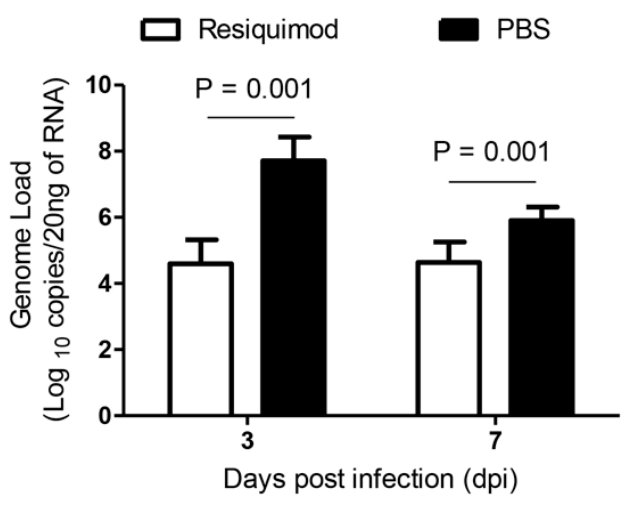

Figure 3. Infectious bronchitis virus (IBV) shedding via oropharyngeal and cloacal routes following infection with IBV M41 in in ovo resiquimod pretreated chickens. ED18 SPF eggs were treated with resiquimod ( $n=10,400 \mu \mathrm{g}$ of resiquimod in $200 \mu \mathrm{L}$ of PBS per egg) or PBS ( $n=15,200 \mu \mathrm{L}$ of PBS per egg) and incubated to hatch. On the day of hatch, the chickens were infected with IBV M41 intratracheally. On 3 and $7 \mathrm{dpi}$ (a) oropharyngeal and (b) cloacal swabs were used for the extraction of RNA and real-time PCR assay was used for the IBV genome quantification. Linear mixed-effects model followed by a pairwise comparison using Tukey's test was used to identify group differences in oropharyngeal and cloacal IBV genome loads. The differences were considered significant at $p \leq 0.001$. The error bars represent \pm SEM.

\subsection{Adjuvant Effect of Resiquimod Following In Ovo Delivery}

The resiquimod (ssRNA) plus IBV killed vaccine group showed higher IFN- $\gamma$ concentration which significantly differ $(p<0.05)$ from IBV killed vaccine alone and control groups in lung (Figure 4a). However, a statistically significant difference between the resiquimod (ssRNA) plus IBV killed vaccine group and the two control groups was not seen although a trend of lower IFN- $\gamma$ production was seen as compared with the resiquimod (ssRNA) plus IBV killed vaccine group. No significant differences were observed between various groups in spleen (Figure $4 \mathrm{~b}$ ) although the concentrations were found to be higher than in lung. 
a.

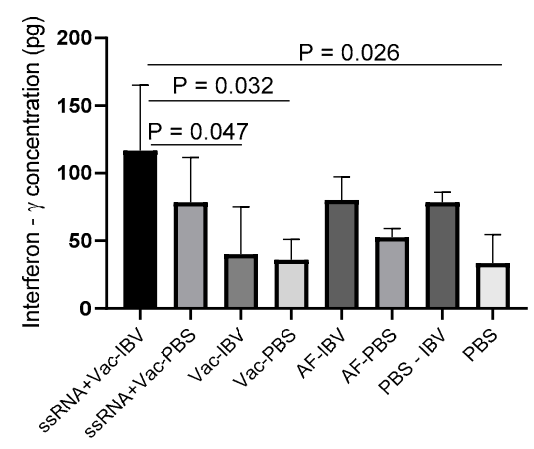

b.

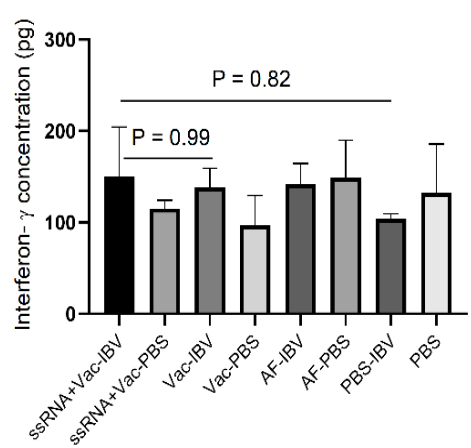

Figure 4. IFN- $\gamma$ production in mononuclear cells of chickens that received in ovo resiquimod plus IBV killed vaccine. ED18 SPF eggs ( $n=6$ in each group) were treated with resiquimod + inactivated IBV vaccine (ssRNA + Vac) $(100 \mu \mathrm{g}$ of resiquimod $+5 \mu \mathrm{g}$ inactivated IBV vaccine in $200 \mu \mathrm{L}$ of PBS per egg), inactivated IBV vaccine (Vac) (5 $\mu$ g inactivated IBV vaccine in $200 \mu \mathrm{L}$ of PBS per egg), allantoic fluid (AF) $(200 \mu \mathrm{L}$ per egg), or PBS (200 $\mu \mathrm{L}$ per egg) and incubated to hatch. At 12 days post- immunization, the chickens ( $n=3$ per group) were euthanized and mononuclear cells harvested from (a) lung and (b) spleen, a subset of each group was stimulated with inactivated IBV vaccine $(5 \mu \mathrm{g})$ and PBS control for $48 \mathrm{~h}$. The IFN- $\gamma$ production was measured by ELISA. The one-way ANOVA followed by Tukey's multiple comparisons test was used to identify the statistical differences between various groups. The differences were considered significant at $p \leq 0.05$ the bars represent mean \pm SEM.

\section{Discussion}

The study described here aimed at investigating the efficacy and involved mediators following pre-hatch delivery of resiquimod against IBV infection encountered post-hatch. First, we found that in ovo delivered resiquimod was effective in enhancing host response characterized by increased recruitment of macrophages and CD8 $\alpha+$ T cells and increased mRNA expression of IFN- $\gamma$ and IL-1 $\beta$ in the lungs. Second, we found that the in ovo delivered resiquimod along with IBV killed vaccine were effective in enhancing IFN- $\gamma$ production following restimulation with inactivated IBV. Finally, the enhanced host responses associated with reduction in IBV shedding early during the experimental period was observed.

In the current study, we saw a significant increase in the expansion of CD8 $\alpha+\mathrm{T}$ cell population in resiquimod pretreated lungs as compared with PBS pretreated control lungs. Although, the mechanisms underlying the ability of resiquimod to increase $\mathrm{CD} 8 \alpha+\mathrm{T}$ cell recruitment in the absence of antigen stimulation is unclear, evidence of a different TLR7 agonist, promoting proliferation of naïve T cells has been observed in vitro in the presence of antigen presenting cells, dendritic cells (DCs) [26]. In addition to $\mathrm{CD} 8 \alpha+\mathrm{T}$ cell recruitment, macrophage recruitment has also been higher in the lungs following pre-hatch delivery of resiquimod. Previously, avian macrophages have been shown to elicit an antiviral response in vitro against avian influenza virus replication [27].

Although it has been shown that type 1 IFNs are induced following resiquimod treatment in other animal models [28], our previous work indicated the lack of production of type 1 IFNs and increased production of IL- $1 \beta$ following treatment of avian macrophage with resiquimod [15,27]. In agreement with the observations of these later studies, a lack of production of type IFNs have been shown in avian macrophages following stimulation of these cells with resiquimod [29]. Although avian macrophages lack expression of type 1 IFNs following resiquimod treatment, macrophages are capable of expressing type 1 IFN mRNA expression in response to other TLR ligands [30,31] However, resiquimod has been shown to produce type 1 IFN mRNA in peripheral blood mononuclear cells (PBMC) originated from chickens $[9,32]$ and this indicates that we require further investigations to observe type 1 IFN response in our in vivo model.

The significant upregulation of IFN- $\gamma$ mRNA was seen in resiquimod pretreated lungs and suggests that resiquimod is capable of promoting the production of cytokines that facilitate Th1 biased adaptive 
immune response [33,34]. Since macrophages and CD8 $\alpha+\mathrm{T}$ cells are known to be sources of IFN- $\gamma[35,36]$, it is possible that the observed IFN- $\gamma$ mRNA expression in our study could have come from the recruited $\mathrm{T}$ cells and macrophages.

Another cytokine mRNA that was induced by resiquimod in our study that could have played a role in recruitment of immune cells in lungs is the IL-1 $\beta$. It has been observed that through TLR stimulation, activated macrophages can secrete IL-1 $\beta$ among other chemokines and cytokines $[30,37]$. Furthermore, IL-1 $\beta$ is a known chemotactic cytokine that traffics macrophages and other immune cells into sites of an injury [38]. This autocrine positive feedback loop could possibly explain the increased recruitment of macrophages into the lung tissue along with an associated increase in IL- $1 \beta$ that we observed. IL-1 $\beta$, originating from avian macrophages, has been shown to elicit antiviral response [27] and it is possible that IL-1 $\beta$ expression in lungs could have played a role in reducing IBV shedding early during the infection.

Correlating with the recruitment of immune cells and upregulation of selected cytokine mRNA by the time of IBV infection (day of hatch), we saw a significant reduction in IBV virus shedding through both oral and fecal routes early during the study in resiquimod pretreated chickens as compared with PBS pretreated chickens. Supporting our findings, in chickens, two previous studies have shown that prophylactic administration of resiquimod to two-week-old chickens, led to significant reduction in IBDV replication [10] and shedding of AIV [16]. Our previous work also recorded that in ovo administration of resiquimod is capable of reducing cloacal shedding of ILTV genome loads [15].

\section{Conclusions}

We have shown that pre-hatch delivery of resiquimod, increased IFN- $\gamma$ and IL-1 $\beta$ gene upregulation, and $\mathrm{CD} 8 \alpha+\mathrm{T}$ cell and macrophage recruitments into the lung tissue of chickens. Next, we found that when resiquimod was administered along with IBV killed vaccine in ovo, resiquimod could act as an adjuvant increasing cell-mediated immune response. The enhanced immune response by in ovo delivered resiquimod correlates with reduced IBV genome loads in cloacal and oropharyngeal routes following IBV encounter post-hatch.

Supplementary Materials: The following is available online at http://www.mdpi.com/2076-393X/8/2/186/s1, Table S1: PCR primers used in RT-PCR assays.

Author Contributions: Conceptualization, funding acquisition, and project management, M.F.A.-C.; Methodology, formal analysis, and investigation, U.D.S.S., M.A. (Mohamed Aboelkhair), M.A. (Mariam Ali), K.P., M.S.A.-C., and A.A.; Original draft preparation, U.D.S.S.; mentoring, U.D.S.S.; review of the manuscript, and editing, M.F.A.-C., G.V.M., and M.C.; Student Supervision, M.F.A.-C. All authors have read and agreed to the published version of the manuscript.

Funding: This study was supported by a joint project funded by the Natural Sciences and Engineering Research Council of Canada (collaborative research and development grant \#EQPEQ/421963-2012), Alberta Livestock and Meat Agency (Alberta Agriculture and Forestry, grant \#2011R037R) and Canadian Poultry Research Council (grant \#AMN048).

Acknowledgments: We would like to acknowledge the staff of the prion/virology animal facility at the Foothill Campus, University of Calgary for the experimental animal management and Grace Kwong for extending support in statistical analysis.

Conflicts of Interest: Authors declare no conflicts of interest.

\section{References}

1. Bande, F.; Arshad, S.S.; Omar, A.R.; Hair-Bejo, M.; Mahmuda, A.; Nair, V. Global distributions and strain diversity of avian infectious bronchitis virus: A review. Anim. Health. Res. Rev. 2017, 18, 70-83. [CrossRef]

2. Cavanagh, D. Coronavirus avian infectious bronchitis virus. Vet. Res. 2007, 38, 281-297. [CrossRef]

3. Hitchner, S.; Winterfield, R.; Appleton, G. Infectious bronchitis virus types: Incidence in the United States. Avian Dis. 1966, 10, 98-102. [CrossRef]

4. Ignjatovic, J.; Sapats, S. Avian infectious bronchitis virus. Revue Scientifique et Technique-Office International des Epizooties 2000, 19, 493-501. [CrossRef] 
5. Kawai, T.; Akira, S. The role of pattern-recognition receptors in innate immunity: Update on Toll-like receptors. Nat. Immunol. 2010, 11, 373. [CrossRef] [PubMed]

6. Brownlie, R.; Allan, B. Avian toll-like receptors. Cell Tissue Res. 2011, 343, 121-130. [CrossRef] [PubMed]

7. Takano, T.; Kondo, H.; Hirono, I.; Endo, M.; Saito-Taki, T.; Aoki, T. Toll-like receptors in teleosts. Dis. Asian Aquac. VII 2011, 197-208.

8. Dockrell, D.; Kinghorn, G. Imiquimod and resiquimod as novel immunomodulators. J. Antimicrob. Chemother. 2001, 48, 751-755. [CrossRef]

9. Annamalai, A.; Ramakrishnan, S.; Sachan, S.; Sharma, B.K.; Anand Kumar, B.S.; Kumar, V.; Badasara, S.K.; Kumar, A.; Saravanan, B.C.; Krishnaswamy, N. Administration of TLR7 agonist, resiquimod, in different types of chicken induces a mixed Th1 and Th2 response in the peripheral blood mononuclear cells. Res. Vet. Sci. 2015, 100, 105-108. [CrossRef]

10. Annamalai, A.; Ramakrishnan, S.; Sachan, S.; Kumar, B.A.; Sharma, B.K.; Kumar, V.; Palanivelu, M.; Varghese, B.P.; Kumar, A.; Saravanan, B. Prophylactic potential of resiquimod against very virulent infectious bursal disease virus (vvIBDV) challenge in the chicken. Vet. Microbiol. 2016, 187, 21-30. [CrossRef]

11. Rook, A.H.; Gelfand, J.C.; Wysocka, M.; Troxel, A.B.; Benoit, B.; Surber, C.; Elenitsas, R.; Buchanan, M.A.; Leahy, D.S.; Watanabe, R. Topical resiquimod can induce disease regression, eradicate malignant $\mathrm{T}$ cells and enhance $\mathrm{T}$ cell effector functions in cutaneous T cell lymphoma. Blood 2015. [CrossRef] [PubMed]

12. Sachan, S.; Ramakrishnan, S.; Annamalai, A.; Sharma, B.K.; Malik, H.; Saravanan, B.; Jain, L.; Saxena, M.; Kumar, A.; Krishnaswamy, N. Adjuvant potential of resiquimod with inactivated Newcastle disease vaccine and its mechanism of action in chicken. Vaccine 2015, 33, 4526-4532. [CrossRef] [PubMed]

13. Abdul-Cader, M.S.; Palomino-Tapia, V.; Amarasinghe, A.; Ahmed-Hassan, H.; De Silva Senapathi, U.; Abdul-Careem, M.F. Hatchery vaccination against poultry viral diseases: Potential mechanisms and limitations. Viral Immunol. 2018, 31, 23-33. [CrossRef] [PubMed]

14. Negash, T.; Al-Garib, S.; Gruys, E. Comparison of in ovo and post-hatch vaccination with particular reference to infectious bursal disease. A review. Vet. Q. 2004, 26, 76-87. [CrossRef] [PubMed]

15. Abdul-Cader, M.S.; De Silva Senapathi, U.; Ahmed-Hassan, H.; Sharif, S.; Abdul-Careem, M.F. Single stranded (ss)RNA-mediated antiviral response against infectious laryngotracheitis virus infection. BMC Microbiol. 2019, 19, 34. [CrossRef] [PubMed]

16. Barjesteh, N.; Shojadoost, B.; Brisbin, J.T.; Emam, M.; Hodgins, D.C.; Nagy, É; Sharif, S. Reduction of avian influenza virus shedding by administration of Toll-like receptor ligands to chickens. Vaccine 2015, 33, 4843-4849. [CrossRef] [PubMed]

17. Tang, Y.; Lu, J.; Wu, P.; Liu, Z.; Tian, Z.; Zha, G.; Chen, H.; Wang, Q.; Wang, Q.; Hou, F. Inactivated vaccine with adjuvants consisting of pattern recognition receptor agonists confers protection against avian influenza viruses in chickens. Vete. Microbiol. 2014, 172, 120-128. [CrossRef]

18. Matoo, J.J.; Bashir, K.; Kumar, A.; Krishnaswamy, N.; Dey, S.; Chellappa, M.M.; Ramakrishnan, S. Resiquimod enhances mucosal and systemic immunity against avian infectious bronchitis virus vaccine in the chicken. Microb. Pathogenesis 2018, 119, 119-124. [CrossRef]

19. Reed, L.J.; Muench, H. A simple method of estimating fifty per cent endpoints. Am. J. Epidemiol. 1938, 27, 493-497. [CrossRef]

20. Abdul-Cader, M.S.; Ahmed-Hassan, H.; Amarasinghe, A.; Nagy, E.; Sharif, S.; Abdul-Careem, M.F. Toll-like receptor (TLR) 21 signalling-mediated antiviral response against avian influenza virus infection correlates with macrophage recruitment and nitric oxide production. J. Gen. Virol. 2017, 98, 1209-1223. [CrossRef]

21. Kameka, A.M.; Haddadi, S.; Jamaldeen, F.J.; Moinul, P.; He, X.T.; Nawazdeen, F.H.P.; Bonfield, S.; Sharif, S.; van Rooijen, N.; Abdul-Careem, M.F. Clodronate treatment significantly depletes macrophages in chickens. Can. J. Vet. Res. 2014, 78, 274-282. [PubMed]

22. Kameka, A.M.; Haddadi, S.; Kim, D.S.; Cork, S.C.; Abdul-Careem, M.F. Induction of innate immune response following infectious bronchitis corona virus infection in the respiratory tract of chickens. Virology 2014, 450, 114-121. [CrossRef] [PubMed]

23. Amarasinghe, A.; Abdul-Cader, M.S.; Nazir, S.; Senapathi, U.D.S.; van der Meer, F.; Cork, S.C.; Gomis, S.; Abdul-Careem, M.F. Infectious bronchitis corona virus establishes productive infection in avian macrophages interfering with selected antimicrobial functions. PloS ONE 2017, 12, e0181801. [CrossRef] [PubMed] 
24. De Silva Senapathi, U.; Abdul-Cader, M.; Amarasinghe, A.; van Marle, G.; Czub, M.; Gomis, S.; Abdul-Careem, M. The In Ovo Delivery of CpG Oligonucleotides Protects against Infectious Bronchitis with the Recruitment of Immune Cells into the Respiratory Tract of Chickens. Viruses 2018, 10, 635. [CrossRef]

25. Pawar, S.D.; Murtadak, V.B.; Kale, S.D.; Shinde, P.V.; Parkhi, S.S. Evaluation of different inactivation methods for high and low pathogenic avian influenza viruses in egg-fluids for antigen preparation. J. Virol. Methods 2015, 222, 28-33. [CrossRef]

26. Wang, C.; Zhou, Q.; Wang, X.; Wu, X.; Chen, X.; Li, J.; Zhu, Z.; Liu, B.; Su, L. The TLR7 agonist induces tumor regression both by promoting CD4+ T cells proliferation and by reversing $\mathrm{T}$ regulatory cell-mediated suppression via dendritic cells. Oncotarget 2015, 6, 1779. [CrossRef]

27. Abdul-Cader, M.S.; Senapathi, U.D.S.; Nagy, E.; Sharif, S.; Abdul-Careem, M.F. Antiviral response elicited against avian influenza virus infection following activation of toll-like receptor (TLR) 7 signaling pathway is attributable to interleukin (IL)-1 $\beta$ production. BMC Res. Notes 2018, 11, 859. [CrossRef]

28. Yrlid, U.; Milling, S.W.F.; Miller, J.L.; Cartland, S.; Jenkins, C.D.; MacPherson, G.G. Regulation of Intestinal Dendritic Cell Migration and Activation by Plasmacytoid Dendritic Cells, TNF- $\alpha$ and Type 1 IFNs after Feeding a TLR7/8 Ligand. J. Immunol. 2006, 176, 5205-5212. [CrossRef]

29. Philbin, V.J.; Iqbal, M.; Boyd, Y.; Goodchild, M.J.; Beal, R.K.; Bumstead, N.; Young, J.; Smith, A.L. Identification and characterization of a functional, alternatively spliced Toll-like receptor 7 (TLR7) and genomic disruption of TLR8 in chickens. Immunology 2005, 114, 507-521. [CrossRef]

30. Barjesteh, N.; Behboudi, S.; Brisbin, J.T.; Villanueva, A.I.; Nagy, É.; Sharif, S. TLR ligands induce antiviral responses in chicken macrophages. PloS ONE 2014, 9, e105713. [CrossRef]

31. Ahmed-Hassan, H.; Abdul-Cader, M.S.; Sabry, M.A.; Hamza, E.; Abdul-Careem, M.F. Toll-like receptor (TLR)4 signalling induces myeloid differentiation primary response gene (MYD) 88 independent pathway in avian species leading to type I interferon production and antiviral response. Virus Res. 2018, 256, 107-116. [CrossRef] [PubMed]

32. Ramakrishnan, S.; Annamalai, A.; Sachan, S.; Kumar, A.; Sharma, B.K.; Govindaraj, E.; Chellappa, M.M.; Dey, S.; Krishnaswamy, N. Synergy of lipopolysaccharide and resiquimod on type I interferon, pro-inflammatory cytokine, Th1 and Th2 response in chicken peripheral blood mononuclear cells. Mol. Immunol. 2015, 64, 177-182. [CrossRef] [PubMed]

33. Otero, M.; Calarota, S.A.; Felber, B.; Laddy, D.; Pavlakis, G.; Boyer, J.D.; Weiner, D.B. Resiquimod is a modest adjuvant for HIV-1 gag-based genetic immunization in a mouse model. Vaccine 2004, 22, 1782-1790. [CrossRef] [PubMed]

34. Thomsen, L.L.; Topley, P.; Daly, M.G.; Brett, S.J.; Tite, J.P. Imiquimod and resiquimod in a mouse model: Adjuvants for DNA vaccination by particle-mediated immunotherapeutic delivery. Vaccine 2004, 22, 1799-1809. [CrossRef]

35. Macatonia, S.E.; Doherty, T.M.; Knight, S.C.; O'Garra, A. Differential effect of IL-10 on dendritic cell-induced T cell proliferation and IFN-gamma production. J. Immunol. 1993, 150, 3755-3765.

36. Szabo, S.J.; Sullivan, B.M.; Stemmann, C.; Satoskar, A.R.; Sleckman, B.P.; Glimcher, L.H. Distinct effects of T-bet in TH1 lineage commitment and IFN- $\gamma$ production in CD4 and CD8 T cells. Science 2002, 295, 338-342. [CrossRef]

37. He, Y.; Franchi, L.; Núñez, G. TLR agonists stimulate Nlrp3-dependent IL-1 $\beta$ production independently of the purinergic P2X7 receptor in dendritic cells and in vivo. J. Immunol. 2013, 190, 334-339. [CrossRef]

38. Koyama, S.; Sato, E.; Masubuchi, T.; Takamizawa, A.; Kubo, K.; Nagai, S.; Isumi, T. Procaterol inhibits IL-1beta-and TNF-alpha-mediated epithelial cell eosinophil chemotactic activity. European Respiratory J. 1999, 14, 767-775. [CrossRef]

(C) 2020 by the authors. Licensee MDPI, Basel, Switzerland. This article is an open access article distributed under the terms and conditions of the Creative Commons Attribution (CC BY) license (http://creativecommons.org/licenses/by/4.0/). 